\title{
A pilot study of a hospital-based injury surveillance system in a secondary level district hospital in India: lessons learnt and way ahead
}

\author{
P. V. M. Lakshmi ${ }^{1 *}$, Jaya Prasad Tripathy ${ }^{1,2}$, Nalinikanta Tripathy ${ }^{1,3}$, Sunita Singh ${ }^{1}$, Deepak Bhatia ${ }^{4}$, \\ Jagnoor Jagnoor ${ }^{5}$ and Rajesh Kumar ${ }^{1}$
}

\begin{abstract}
Background: Reliable epidemiological information on injury burden and pattern is essential to formulate effective injury control and prevention strategies. Injury surveillance systems are globally gaining ground as a tool for collecting such systematic data on injuries, but less so in low and middle income countries. This study describes the experience of setting up a District Level Hospital-Based Injury Surveillance System in India and the pattern of injuries encountered therein.

Methods: A prospective study was conducted during Jan-Dec 2012 at the emergency department of a District Hospital in Fatehgarh Sahib in a North Indian state of Punjab. A comprehensive injury proforma was devised to record information on all injury cases reporting to the hospital. Emergency Medical Officers were trained to record data.

Results: A total of 649 injuries were reported in 2012. The surveilance system used the existing resources at the hospital to collect data without the need for additional manpower, equipments etc. About $78 \%$ of injuries reported were unintentional in nature. More than half (52.9\%) of the patients had injuries due to Road Traffic Crashes. Head $(29.7 \%)$ was the most common site of injury. Incised injury (50.2\%) was the most common type of injury and most of the injuries occurred while travelling (61.8\%).
\end{abstract}

Conclusion: Developing better and sustainable systems of routine injury surveillance or trauma registries is essential to generate reliable information for formulating effective intervention policies.

Keywords: Injury surveillance, Hospital-based, India

\section{Background}

Injuries rank among the leading causes of morbidity and mortality in the world with a steady increase in developing countries like India. About 5.8 million people die each year as a result of injuries. This accounts for $10 \%$ of the world's deaths, $32 \%$ more than the number of fatalities that result from malaria, tuberculosis and HIV/ AIDS combined (Injuries and violence 2010). Approximately $90 \%$ of the global injury-related deaths occur in

\footnotetext{
* Correspondence: pvm_lakshmi@yahoo.com

${ }^{1}$ Department of Community Medicine \& School of Public Health, Post Graduate Institute of Medical Education \& Research, Chandigarh, India Full list of author information is available at the end of the article
}

low and middle income countries, like India (Injuries and violence 2010). India is a LMIC with more than one billion people, and one of the fastest growing economies in the world. The economic growth has also meant a rapidly increasing number of vehicles sold every year (around six million) and one of the highest reported mortality rates from road traffic injuries in the world (Garg \& Hyder 2006). Traffic fatalities have increased by about $5 \%$ per year from 1980 to 2000 , and since then have increased by about $8 \%$ per year (Mohan et al. 2009). The burden of traumatic injuries in India is certainly high, but remains ill-defined and poorly quantified. 
For example, there are currently no comprehensive studies, to our knowledge, that document the burden of non-fatal injuries in India. Systematic and scientific efforts in injury prevention and control have gained little momentum, largely due to lack of data on the epidemiology of injuries. Data on injuries is essential to prioritize evidence based safety strategies and prevention efforts. Reliable estimates on injury burden and pattern will also aid in organization and delivery of acute trauma care. Thus, there is greater emphasis on the need to generate reliable and consistent information on the pattern and distribution of injuries so as to design effective prevention strategies. Consequently, injury surveillance systems are widely gaining ground as a tool for collecting such systematic data on injuries. Although they are well-developed in high resource settings, they are almost non-existent in resource poor Low and Middle income countries (LMICs). This study describes the experience of setting up an Injury Surveillance System in a District Level Hospital in India and the pattern of injuries encountered therein. It also aimed at exploring the feasibility of a secondary level hospital-based surveillance system in a resource poor setting with high injury burden and also to understand its challenges and constraints.

\section{Methods}

\section{Study setting}

The study was carried out at the emergency department of District Hospital, Fatehgarh Sahib, Punjab. Fatehgarh Sahib is a district in Punjab, a state in North India with a population of approximately 600000 . The district has a reasonably good spread of health services. It has 1 District Hospital, 1 sub-divisional hospital, 2 primary health centres (PHCs), 3 community health centres $(\mathrm{CHCs})$ and 11 Mini-PHCs besides other rural hospitals and dispensaries. An injury surveillance project was started at the Emergency Department (ED) of the District Hospital after taking due permission from the State Surveillance Unit and the concerned district health officials. The District Hospital provides specialized secondary care services catering to a population of around 0.6 million. It is staffed by specialists from the departments of medicine, surgery, pediatrics, orthopedics, anesthesia, dermatology, psychiatry, ophthalmology, pathology, dental and 5 medical officers. A comprehensive injury proforma was developed based on WHO Injury Surveillance guidelines (Holder et al. 2001). The questionnaire had three major sections: patient demographics, details of the injury and events after injury. The details of the injury, amongst others, included the intent, mechanism, nature and site of injury, activity that the patient was involved in when the injury occurred, place of injury and alcohol or substance use. (Attached as annexure) The Emergency Medical Officers were trained to fill the forms. Data were collected for all patients admitted to the emergency department during the period January-December 2012. An electronic database was developed on Epi Info. The data collected was entered into the database and exported to SPSS 16 for analysis (SPSS Inc 2007). Checks were built into the EpiInfo data collection tool to ensure data quality. Random check of the data $(10 \%)$ was also done.

\section{Description of the injury surveillance system}

Injury Surveillance System was initiated at the District Hospital in Fatehgarh Sahib following discussions with the Civil Surgeon, medical officers and other key officials. Medical Officers in the hospital were trained to collect information from the patients who visited the emergency department with an injury on a structured proforma. Upon arrival of a patient in the emergency department, routine admission procedures and management as per the treatment protocols were followed. No changes were made to the usual care of the patient. The trained emergency medical officer after stabilizing the patient collected information on socio-demographics and injury history from the attendant or the patient, if able, after informed consent. The intent, mechanism, site and nature of injury was based on the assessment of the Emergency Medical Officer (EMO) filling the form. The data were entered on a weekly basis at the Surveillance Unit at School of Public Health, Post Graduate Institute of Medical Education and Research, (PGIMER) Chandigarh, India, which is a premier tertiary care medical institute. The Injury Surveillance System was coordinated by the Surveillance Unit at School of Public Health, PGIMER led by the Head of the Department and the Faculty of Epidemiology at the School of Public Health. Other members of the unit were Senior and Junior Residents of Community Medicine, Demonstrator in Epidemiology, Public Health Nurse and a Data Entry Operator.

The data quality was ensured by the Public Health Nurse, Senior Resident and the faculty visiting the hospital weekly by checking the data of the form with the data available in the registers of the emergency department on the numbers and whether all the columns were properly filled or not. Data were entered by a Data Entry Operator at the Surveillance Unit at School of Public Health, PGIMER, Chandigarh.

\section{Data analysis}

Descriptive statistics such as percentages have been used to summarize categorical variables. Chi-square test was done to study the association between different types of injuries and demographic variables such as age group and sex. 


\section{Results}

Out of a total of 1548 patients admitted to the emergency department in the year 2012, 649 (42\%) cases of injuries were reported through the surveillance system. A total of 628 medico-legal cases (MLCs) were registered in the same year. As most of the medico legal cases comprises of injuries, the number recorded in the surveillance system should not be less than the reported medico legal cases. (Medico-Legal Case are defined as a case of injury or ailment and like in which investigation by the law-enforcing agencies is essential to fix the responsibility regarding the causation of the said injury or ailment) (Wikipedia contributors). The surveilance system used the existing resources at the hospital to collect data without the need for additional manpower, equipments etc.

\section{Basic socio-demographic profile of patients}

A total of 649 patients were reported by the injury surveillance system during the study period. Around $40 \%$ (254) of patients belonged to the age group 25-44 followed by 45-64 with $21.7 \%$ (140). More males (80\%, 517) reported injuries as compared to females (20\%, 130) Table 1.

\section{Profile of injuries}

About $78 \%$ (493) of injuries reported were unintentional followed by intentional injuries in $19 \%$ (122) of cases. More than half $(52.9 \%, 338)$ of the patients had injuries due to road traffic crashes, head $(29.7 \%, 190)$ was the most common site of injury. Among the nature of injuries, incised wound (clean cut wound usually by a sharp instrument) (50.2 \%) was the most common. (See Table 1) Around $90 \%$ (259) of crash victims did not wear a helmet or seatbelt. Among the cases of road traffic crashes, most of them were travelling on a twowheeler $(51.8 \%, 171)$, followed by car/auto $(17.5 \%, 57)$ and pedestrians $(14.4 \%, 47)$ (data not shown).

Table 2 provides the cross tabulations between the intent and the nature of injury. Nearly half $(50.1 \%, 247)$ of unintentional injuries were cut/open wounds followed by fractures $(10.8 \%, 53)$. Cut/open wounds accounted $66.7 \%, 8)$ of self-inflicted injuries and $(42.6 \%, 52)$ of intentional injuries. (See Table 2) Table 3 gives the distribution of intent of injury by age group and sex. Both intentional and unintentional injuries were common among males in the age group 25-44. Nearly (13.1\%, 16) of intentional injuries were among females in the age group 25-44. (See Table 3) Table 4 shows the distribution of mechanism of injury by age group and sex. Road traffic crashes were most common among males in the age-group $25-44(35.5 \%, 120)$ followed by $45-64$ $(18.0 \%, 61)$. Fall injury was most common among males in the age-group 15-24 $(24.7 \%, 20)$ closely followed by males in $25-44(23.5,19)$ and $0-14$ years $(18.5 \%, 15)$. (See Table 4) The proportion of intentional injuries/violence were significantly higher among females as compared to males. Cut wounds were significantly higher among males than females (See Table 5). Self harm was more common in the age group of $15-24$ years where as other intents of injury were common in the age group of $25-44$ years. Falls were significantly higher in the age of 45 years and above as compared to other nature of injuries. Sports related injuries were common among ages less than 24 years whereas in other age groups injuries occurred either during work or during travel. (See Table 6) Seasonal distribution of cases showed two peaks in the months of February and August (Fig. 1).

\section{Discussion}

This is probably the first study in India which looked at the profile of injuries admitted to the emergency department of a district level hospital and feasibility of setting up of an injury surveillance system at a secondary level for integration into the routine surveillance system. As against retrospective record based studies in the literature, this study was the result of a prospective injury surveillance project. Thus considerable attention could be paid towards collection of good quality data through repeated trainings and discussions with the Emergency Medical Officers (EMOs) who were filling the forms in spite of their busy schedules. These trainings or discussions were held when one of the authors used to go to the emergency department weekly for collection of filled forms. Considering the fact that around 1548 patients visited the emergency department in the year of the study (daily load of around 5-7), districts hospitals are not heavy load emergency settings thereby ruling out the factor of time constraint.

Males were predominantly involved in injuries similar to previous studies in different settings (Yamuragiye et al. 2013; Santikarn et al. 1999; Arscott-Mills et al. 2002; Uthkarsh et al. 2012; Chinh et al. 2007). A systematic review of injury surveillance systems in China reported 12 studies all of whom showed male preponderance ranging fom 1.9:1 to 3.1:1 (Fitzharris et al. 2011). Majority of the injuries belonged to the age group 25-44 followed by 45-64 similar to several other studies (Fitzharris et al. 2011; Deng et al. 2010). This preponderance for adult males could be attributed to the fact that males in this age group tend to be more involved in outdoor occupations with wide ranging travel needs and other high risk activities (Holder et al. 2001).

Seasonal variation with a bimodal peak was observed with maximum number of injuries and crashes reported during the months of February and August. This might 
Table 1 Socio-demographic profile and characteristics of injuries among patients attending the emergency of a Secondary Level Hospital in District Fatehgarh Sahib, Punjab, India, $2012(N=649)$

\begin{tabular}{|c|c|}
\hline Characteristics & Number (\%) \\
\hline \multicolumn{2}{|l|}{ Sex } \\
\hline Male & $517(80)$ \\
\hline Female & $130(20)$ \\
\hline Not recorded & $02(0)$ \\
\hline \multicolumn{2}{|l|}{ Residence } \\
\hline Urban & $302(47)$ \\
\hline Rural & $312(48)$ \\
\hline Not recorded & $35(5)$ \\
\hline \multicolumn{2}{|l|}{ Age group } \\
\hline $0-14$ & $53(8.2)$ \\
\hline $15-24$ & $176(27.1)$ \\
\hline $25-44$ & $254(39.1)$ \\
\hline $45-64$ & $140(21.6)$ \\
\hline$>64$ & $22(3.4)$ \\
\hline Not recorded & $04(0.6)$ \\
\hline \multicolumn{2}{|l|}{ Intent of injury } \\
\hline Unintentional & $493(78.1)$ \\
\hline Intentional & $122(19.4)$ \\
\hline Self-harm & $12(1.9)$ \\
\hline Others & $4(0.6)$ \\
\hline Not recorded & $18(2.8)$ \\
\hline \multicolumn{2}{|l|}{ Site of injury ${ }^{c}$} \\
\hline Head & $190(29.3)$ \\
\hline Face & $142(21.9)$ \\
\hline Upper limb & $140(21.6)$ \\
\hline Lower limb & $102(15.7)$ \\
\hline Chest & $26(4.0)$ \\
\hline Spinal & $16(2.5)$ \\
\hline Neck & $12(1.8)$ \\
\hline Abdomen & $10(1.6)$ \\
\hline Bone & $1(0.1)$ \\
\hline Not recorded & $64(10)$ \\
\hline \multicolumn{2}{|l|}{ Nature of Injuryc } \\
\hline Incised wound & $326(50)$ \\
\hline Fracture/Dislocation & $113(17)$ \\
\hline Abrasion & $112(17)$ \\
\hline Contusion & $44(7)$ \\
\hline Concussion & $36(6)$ \\
\hline Laceration & $35(5)$ \\
\hline Burn & $12(2)$ \\
\hline Others $^{\mathrm{a}}$ & $11(2)$ \\
\hline Not recorded & $36(6)$ \\
\hline
\end{tabular}

Table 1 Socio-demographic profile and characteristics of injuries among patients attending the emergency of a Secondary Level Hospital in District Fatehgarh Sahib, Punjab, India, 2012 ( $N=649$ ) (Continued)

\begin{tabular}{|c|c|}
\hline \multicolumn{2}{|l|}{ Activity during injury } \\
\hline Travelling & $330(51)$ \\
\hline Working & $150(23)$ \\
\hline Sports & $18(3)$ \\
\hline Education & $18(3)$ \\
\hline Others & $23(3)$ \\
\hline Not recorded & $110(17)$ \\
\hline \multicolumn{2}{|l|}{ Mechanism of injury } \\
\hline Road Traffic Crash & $338(52)$ \\
\hline Quarrel & $110(17)$ \\
\hline Fall & $80(12)$ \\
\hline Stab cut & $36(6)$ \\
\hline Other blunt force & $22(3)$ \\
\hline Animal bite & $20(3)$ \\
\hline Fire & $7(1)$ \\
\hline Poisoning & $5(1)$ \\
\hline Others $^{b}$ & $19(3)$ \\
\hline Not recorded & $12(2)$ \\
\hline \multicolumn{2}{|l|}{ Outcome of injury } \\
\hline Treated and discharged & $336(51.8)$ \\
\hline Admitted to indoor wards & $171(26.3)$ \\
\hline Referred to higher centres & $109(16.8)$ \\
\hline Death & $6(0.9)$ \\
\hline LAMA & $6(0.9)$ \\
\hline Not recorded & $21(3.2)$ \\
\hline
\end{tabular}

be probably due to foggy conditions in the month of February and slippery roads due to rains during August. However, some evidence in the literature suggests that injuries peak during the summer months of June-August (Foltran et al. 2013; Morrison et al. 1999). There is a sudden dip in the cases in the months of May to July. This may be due to underreporting because of lack of supervision due to non availability of staff during this period. Sustained motivation and monitoring will improve the data collection process by the system. Political commitment in the form of integration along with the existing surveillance system is essential for sustainability.

More than half of the patients admitted to an emergency department of a hospital sustained road traffic injuries similar to previous studies in low and middle income countries countries (Yamuragiye et al. 2013; Uthkarsh et al. 2012; Chinh et al. 2007; Zavala et al. 2008; 
Table 2 Injuries by nature of injury and intent among patients attending the emergency of a Secondary Level Hospital in District Fatehgarh Sahib, Punjab, India, 2012

\begin{tabular}{|c|c|c|c|c|c|c|}
\hline Intent of Injury & Unintentional & Intentional & Self-harm & Others & Unknown & Total \\
\hline Nature of injury & No. (\%) & No. (\%) & No. (\%) & No. (\%) & No. (\%) & No. (\%) \\
\hline Incised wound & $234(42.9)$ & $79(62.7)$ & $8(47.1)$ & $1(25)$ & $4(12.5)$ & $326(45)$ \\
\hline Contusion/abrasion & $128(23.4)$ & $20(15.9)$ & $5(29.4)$ & $1(250$ & $2(6.3)$ & $156(21.5)$ \\
\hline Fracture & $86(15.8)$ & $8(6.3)$ & $2(11.8)$ & 0 & $16(50)$ & $113(15.6)$ \\
\hline Concussion & $30(5.5)$ & $3(2.4)$ & $0(0)$ & 0 & $3(9.4)$ & $36(5.0)$ \\
\hline Laceration & $29(5.3)$ & $2(1.6)$ & $0(0)$ & $1(25)$ & $3(9.4)$ & $35(4.8)$ \\
\hline Burn & $11(2.0)$ & $0(0)$ & $1(5.9)$ & 0 & $0(0)$ & $12(1.7)$ \\
\hline Others & $7(1.3)$ & $4(3.2)$ & $1(5.9)$ & 0 & $0(0)$ & $11(1.5)$ \\
\hline Unknown & $21(3.8)$ & $10(7.9)$ & $0(0)$ & $1(25)$ & $4(12.5)$ & $36(5.0)$ \\
\hline Total & $546(100)$ & $126(100)$ & $17(100)$ & $4(100)$ & $32(100)$ & $725(100)$ \\
\hline
\end{tabular}

John et al. 2008). However few studies have reported fall injury as the most common mechanism of injury (Musharrafieh et al. 2011; Cardona et al. 2008). Worldwide road traffic injuries and falls are among the top leading causes of injuries in different settings. Road traffic injuries were mostly young adult males similar to most other studies (Arscott-Mills et al. 2002; Uthkarsh et al. 2012; John et al. 2008; Cardona et al. 2008; Mtonga \& Zavala 2008; Ganveer \& Tiwari 2005; Dandona et al. 2006; Jirojwong et al. 2002; Singh \& Goel 2011). Several studies have reported that two-wheelers are most vulnerable to crashes similar to the findings in the present study (Santikarn et al. 1999; Uthkarsh et al. 2012; Chinh et al. 2007; Cardona et al. 2008; Jirojwong et al. 2002; Singh \& Goel 2011).

Fall injuries were common in the younger age group of 25-44 mostly related to work or travel followed by $0-14$ and predominantly among males similar to another study by Grivna et al (Grivna et al. 2014). On the contrary, previous studies have shown that falls were a significant cause of both death and injury in women and older adults in high income countries and in India as well (Cardona et al. 2008). This difference in age distribution of falls might be due to the poor health seeking behaviour of elderly and tendency to seek medical care only when the condition becomes severe (WHO 2007). Also most of the falls in the eldery age group do not result in serious injuries (Tripathy et al. 2015).

In the present study, majority of the falls occurred at home as against workplace in other studies (Cardona et al. 2008; Grivna et al. 2014; Tuma et al. 2013; $\mathrm{Ng}$ et al. 2010). The high rates of falls in younger males at home indicate the high level of risk encountered by men and older children in rural India as they go about their usual household and playful activites. However, we need to carry out further studies to explore this in further details.

Among the patients who were referred, nearly $76 \%$ of them had encountered a road traffic crash. About $66 \%$ of the patients referred had injuries on head and face. Also five out of six deaths were as a consequence of road traffic injuries. Thus road traffic injuries account for majority of severe injuries thereby demanding immediate attention. Thus, the feasibility of establishing well equipped acute head injury units and a responsive referral system at the district level needs to be researched upon.

Around $25 \%$ of patients who had sustained road traffic injuries were under the influence of alcohol. Nearly

Table 3 Injuries by age-group, sex and intent among patients attending the emergency of a Secondary Level Hospital in District Fatehgarh Sahib, Punjab, India, 2012

\begin{tabular}{|c|c|c|c|c|c|c|c|c|c|c|c|c|c|c|c|}
\hline \multirow{2}{*}{$\begin{array}{l}\text { Age and sex } \\
\text { Intent }\end{array}$} & \multicolumn{2}{|l|}{$0-14$} & \multicolumn{2}{|l|}{$15-24$} & \multicolumn{2}{|l|}{$25-44$} & \multicolumn{2}{|l|}{$45-64$} & \multicolumn{2}{|l|}{$>64$} & \multicolumn{2}{|c|}{ Unknown } & \multicolumn{2}{|l|}{ Total } & \multirow[t]{2}{*}{ Overall } \\
\hline & M & $\mathrm{F}$ & $M$ & $\mathrm{~F}$ & $\bar{M}$ & $\mathrm{~F}$ & $M$ & $\mathrm{~F}$ & $M$ & $\mathrm{~F}$ & $M$ & $\mathrm{~F}$ & M & $\mathrm{F}$ & \\
\hline Unintentional & $35(7)$ & $14(3)$ & $113(23)$ & $16(3)$ & $164(33)$ & $31(6)$ & 79 (16) & $24(5)$ & $13(3)$ & $4(1)$ & $0(0)$ & $0(0)$ & $404(82)$ & $89(18)$ & 493 \\
\hline Intentional & $0(0)$ & $0(0)$ & $30(25)$ & $7(6)$ & $37(30)$ & $16(13)$ & $22(18)$ & $7(6)$ & $0(0)$ & $3(2.5)$ & $0(0)$ & $0(0)$ & $89(73)$ & $33(27)$ & 122 \\
\hline Self-harm & $1(8)$ & $0(0)$ & $5(42)$ & $1(8)$ & $1(8)$ & $0(0)$ & $3(25)$ & $0(0)$ & $1(8)$ & $0(0)$ & $0(0)$ & $0(0)$ & $11(92)$ & $1(8)$ & 12 \\
\hline Other & $0(0)$ & $0(0)$ & $1(25)$ & $1(25)$ & $1(25)$ & $0(0)$ & $0(0)$ & $1(25)$ & $0(0)$ & $0(0)$ & $0(0)$ & $0(0)$ & $2(50)$ & $2(50)$ & 4 \\
\hline Unknown & $2(11)$ & $1(6)$ & $2(11)$ & $0(0)$ & $2(11)$ & $2(11)$ & $2(11)$ & $2(11)$ & $1(6)$ & $0(0)$ & $2(11)$ & $2(11)$ & $11(61)$ & $7(39)$ & 18 \\
\hline Total & $38(6)$ & $15(2)$ & $151(23)$ & $25(4)$ & 205 (32) & 49 (8) & $106(16)$ & $34(5)$ & $15(2)$ & $7(1)$ & $2(0)$ & $2(0)$ & $517(80)$ & $132(20)$ & 649 \\
\hline
\end{tabular}


Table 4 Injuries by age-group, sex and mechanism of injury among patients attending the emergency of a Secondary Level Hospital in District Fatehgarh Sahib, Punjab, India, 2012

\begin{tabular}{|c|c|c|c|c|c|c|c|c|c|c|c|c|c|c|c|}
\hline \multirow[t]{2}{*}{ Age \& Sex } & \multicolumn{2}{|l|}{$0-14$} & \multicolumn{2}{|l|}{$15-24$} & \multicolumn{2}{|l|}{$25-44$} & \multicolumn{2}{|l|}{$45-64$} & \multicolumn{2}{|l|}{$>64$} & \multicolumn{2}{|c|}{ Unknown } & \multicolumn{2}{|l|}{ Total } & \multirow[t]{2}{*}{ Total } \\
\hline & $\bar{M}$ & $\mathrm{~F}$ & $\bar{M}$ & $\mathrm{~F}$ & $\bar{M}$ & $\mathrm{~F}$ & $\bar{M}$ & $\mathrm{~F}$ & $\bar{M}$ & $\mathrm{~F}$ & $\mathrm{M}$ & $\mathrm{F}$ & $\bar{M}$ & $\mathrm{~F}$ & \\
\hline Road Traffic Crash & $14(4.2)$ & $8(2.4)$ & $65(19.2)$ & $10(3.0)$ & $120(35.5)$ & $23(7.1)$ & $61(18.0)$ & $19(5.6)$ & $12(3.6)$ & $4(1.2)$ & $0(0.0)$ & $2(0.6)$ & $272(80.5)$ & $66(19.5)$ & $338(100)$ \\
\hline Quarrel & $0(0.0)$ & $0(0.0)$ & $27(24.6)$ & $6(5.4)$ & $32(29.1)$ & $16(14.5)$ & $20(18.2)$ & $6(5.5)$ & $0(0.0)$ & $3(2.7)$ & $O(0.0)$ & $0(0.0)$ & 79 (71.8) & $31(28.2)$ & $110(100)$ \\
\hline Fall & $15(18.5)$ & $6(7.4)$ & $20(24.7)$ & $2(2.5)$ & $19(23.5)$ & $4(4.9)$ & $8(9.9)$ & $6(7.4)$ & $0(0.0)$ & $0(0.0)$ & $0(0.0)$ & $0(0.0)$ & $62(77.5)$ & $18(22.5)$ & $80(100)$ \\
\hline Stab/cut & $4(11.1)$ & $1(2.8)$ & $17(47.2)$ & $2(5.6)$ & $6(16.7)$ & $1(2.8)$ & $4(11.1)$ & $0(0.0)$ & $1(2.8)$ & $0(0.0)$ & $0(0.0)$ & $0(0.0)$ & $32(88.9)$ & $4(11.1)$ & $36(100)$ \\
\hline Other blunt force & $3(13.6)$ & $0(0.0)$ & $8(36.4)$ & $0(0.0)$ & $6(27.3)$ & $0(0.0)$ & $3(13.6)$ & $1(4.5)$ & $1(4.5)$ & $0(0.0)$ & $0(0.0)$ & $0(0.0)$ & $21(95.5)$ & $1(4.5)$ & $22(100)$ \\
\hline Animal bite & $1(5.0)$ & $0(0.0)$ & $3(15.0)$ & $1(5.0)$ & $8(40.0)$ & $3(15.0)$ & $2(10.0)$ & $2(10.0)$ & $0(0.0)$ & $0(0.0)$ & $0(0.0)$ & $0(0.0)$ & $14(0.70)$ & $6(0.30)$ & $20(100)$ \\
\hline Fire/Heat & $0(0.0)$ & $0(0.0)$ & $1(14.3)$ & $0(0.0)$ & $3(42.9)$ & $2(28.6)$ & $1(14.3)$ & $0(0.0)$ & $0(0.0)$ & $0(0.0)$ & $0(0.0)$ & $0(0.0)$ & $5(71.4)$ & $2(28.6)$ & $7(100)$ \\
\hline Poisoning & $0(0.0)$ & $0(0.0)$ & $3(60.0)$ & $0(0.0)$ & $1(20.0)$ & $0(0.0)$ & $1(20.0)$ & $0(0.0)$ & $0(0.0)$ & $0(0.0)$ & $0(0.0)$ & $0(0.0)$ & $5(100.0)$ & $0(0.0)$ & $5(100)$ \\
\hline Drowning & $0(0.0)$ & $0(0.0)$ & $0(0.0)$ & $0(0.0)$ & $1(100.0)$ & $0(0.0)$ & $0(0.0)$ & $0(0.0)$ & $0(0.0)$ & $0(0.0)$ & $0(0.0)$ & $0(0.0)$ & $1(100.0)$ & $0(0.0)$ & $1(100)$ \\
\hline Gun shot & $1(100)$ & $0(0.0)$ & $0(0.0)$ & $0(0.0)$ & $0(0.0)$ & $0(0.0)$ & $0(0.0)$ & $0(0.0)$ & $0(0.0)$ & $0(0.0)$ & $0(0.0)$ & $0(0.0)$ & $1(100.0)$ & $0(0.0)$ & $1(100)$ \\
\hline Other & $0(0.0)$ & $0(0.0)$ & $3(20.0)$ & $3(20.0)$ & $4(26.7)$ & $0(0.0)$ & $4(26.7)$ & $0(0.0)$ & $1(6.7)$ & $0(0.0)$ & $2(11.8)$ & $0(0.0)$ & $14(82.3)$ & $3(17.7)$ & 17 (100) \\
\hline Unknown & $0(0.0)$ & $0(0.0)$ & $4(33.3)$ & $1(8.3)$ & $5(41.7)$ & $0(0.0)$ & $2(16.7)$ & $0(0.0)$ & $0(0.0)$ & $0(0.0)$ & $0(0.0)$ & $0(0.0)$ & $11(91.7)$ & $1(8.3)$ & $12(100)$ \\
\hline Total & $38(5.8)$ & $15(2.3)$ & $151(23.3)$ & $25(3.8)$ & 205 (31.6) & $49(7.6)$ & $106(16.3)$ & $34(5.2)$ & $15(2.3)$ & $7(1.1)$ & $2(0.3)$ & $2(0.3)$ & $517(79.7)$ & $132(20.3)$ & 649 (100) \\
\hline
\end{tabular}


Table 5 Association of intent, nature, activity during injury and mechanism of injury with sex among patients attending the emergency of a Secondary Level Hospital in District Fatehgarh Sahib, Punjab, India, 2012

\begin{tabular}{lllll}
\hline Type of injury & Male $n(\%)$ & Female $n(\%)$ & Total $N$ & $P$-value \\
\hline Intent of injury & & & & \\
Unintentional & $403(82)$ & $89(18)$ & 493 & 0.001 \\
Intentional & $89(73)$ & $33(27)$ & 122 & \\
Self-harm & $11(92)$ & $1(8)$ & 12 & \\
Nature of injury & & & & \\
Fracture & $51(81)$ & $12(19)$ & 63 & 0.03 \\
Cut wound & $259(84)$ & $51(16)$ & 310 & \\
Concussion & $14(67)$ & $7(33)$ & 21 & \\
Others & $135(74)$ & $47(26)$ & 182 & \\
Activity during injury & & & & \\
Work & $111(74)$ & $39(26)$ & 150 & 0.14 \\
Travelling & $266(81)$ & $64(19)$ & 330 & \\
Sports & $17(94)$ & $1(6)$ & 18 & \\
Others & $33(81)$ & $8(19)$ & 41 & \\
Mechanism of injury & & & & \\
Road Traffic Crash & $274(81)$ & $64(19)$ & 338 & 0.06 \\
Fall & $62(78)$ & $18(22)$ & 80 & \\
Quarrel & $79(72)$ & $31(28)$ & 110 & \\
Others & $94(86)$ & $16(14)$ & 110 & \\
\hline
\end{tabular}

$45 \%$ of such crashes were reported during the weekends similar to other studies whereas some studies also reported more crashes during weekdays (Ricci et al. 2008; Hijar et al. 2000). Thus strict penalties should be imposed on the offenders and at the same time public should be made aware of the risk of crashes in case of drinking while driving. Around $90 \%$ of those who sustained road traffic injuries while riding a vehicle did not wear a helmet or seat belt. Four out five deaths due to road traffic crash had head and neck injuries which could have been avoided by the use of helmets. Among those who did not wear a helmet, $42 \%$ (92) had head injuries while $25 \%$ (54) suffered injuries to the face. Also, among those who wore a helmet, around $30 \%$ received head injuries which probably suggests overreporting of helmet use due to soial desirability bias or use of helmets which do not conform to the safety standards. This mandates strict legislative action and awareness activities. With such a large share of road traffic crashes among injury cases and especially among severe injury cases, there is an urgent need to put injury prevention policy at the forefront rather than divesting large volume of resources towards acute trauma care.

Lack of reliable information on injury deaths, disabilities and hospitalizations puts injury quite low on the national public health agenda which leads to poor funding opportunities and scarcity of resources. A robust system of routine injury surveillance is essential to generate data for effective decision making. Injury surveillance can identify, monitor and prevent injuries and their risk factors (Holder et al. 2001; Forjuoh \& Gyebi-Ofosu 1993; Halperin 1996). There are other examples of emergency based surveillance systems such as the Weapon Related Injury Surveillance System (WRISS) in the United States (Barber et al. 1998) which was implemented to track firearm related injuries. The Violence Related Injury Surveillance System (VRISS), Australian National Injury Surveillance and Prevention Program (NISPP) and the Canadian Hospital Injury Reporting and Prevention Program (CHIRPP) have also used emergency department data to describe the profile of injuries (Ward et al. 2002; Australian National Injury Surveillance Unit (NISU); MacKenzie \& Pless 1999). National injury surveillance systems have also been initiated in Asian countries like Thailand and China. Sentinel surveillance system in China covers $10 \%$ of the population. The sentinel data have been used to estimate overall injury burden, identify leading risk factors and high-risk groups (Li \& Baker 1991). Thailand also initiated a provincial injury surveillance system with reportingfrom five large hospitals in Bangkok and four regions of the country. The system reported coverage of $98.8 \%$, whereas completeness and reliability of recording ranged from 80.6-100 \% (Santikarn et al. 1999). In another similar resource constraint setting in the Sub-saharan Africa, a trauma registry and injury severity measurement were found to be feasible and useful to assess the effectiveness and efficiency of acute care for the injured (Kobusingye \& Lett 2000).

In this study, the data on the actual number of patients with injuries admitted to the emergency department could not be obtained. However, the surveillance system could capture almost all the medico-legal cases although the proportion of such cases captured by the surveillance system could not be ascertained. There might also be cases of injuries which were not registered as medico-legal cases. These are the cases with injuries not considered to have any medico-legal implications by the physician based on the circumstances that led to the injury such as injuries sustained due to a fall at home caused by a slippery surface. Thus the decision to register a medico-legal is with the treating physician. If there is any suspicion regarding the causation of the injury, he might call the police and register a medico-legal case.

Because emergency department surveillance generates large numbers of injury records in a short period of time, the cost per injury of collecting data at emergency departments is lower than for a population based survey (Mulder 1997). The surveillance system was able to capture injury related information in a simple one-page 
Table 6 Association of intent, nature, activity during injury and mechanism of injury with age among patients attending the emergency of a Secondary Level Hospital in District Fatehgarh Sahib, Punjab, India, 2012

\begin{tabular}{|c|c|c|c|c|c|c|c|}
\hline Type of injury & $0-14$ N (\%) & $15-24 N(\%)$ & 25-44 N (\%) & $45-59 N(\%)$ & $>=60 \mathrm{~N}(\%)$ & Total $N$ & $P$-value \\
\hline \multicolumn{8}{|l|}{ Intent of injury } \\
\hline Unintentional & 49 (10) (10.0) & $129(26)(26.2)$ & $195(40)$ & 88 (18) (17.9) & 31 (6) (6.3) & $492(100)$ & \multirow[t]{3}{*}{0.03} \\
\hline Intentional & $0(0)$ & $37(30)$ & $53(44)$ & 23 (19) (18.8) & $9(7)$ & $122(100)$ & \\
\hline Self-harm & $1(8)$ & $6(50)$ & $1(8)$ & $3(25)$ & $1(8)$ & $12(100)$ & \\
\hline \multicolumn{8}{|l|}{ Nature of injury } \\
\hline Fracture & $4(7)$ & $12(19))$ & $20(32)$ & $22(35)$ & $4(7)$ & $62(100)$ & \multirow[t]{4}{*}{0.03} \\
\hline Cut wound & $28(9)$ & $91(29)$ & $119(39)$ & $51(17)$ & $20(6)(6.5)$ & $309(100)$ & \\
\hline Concussion & $0(0)$ & $06(29)$ & $09(42)$ & $4(19)$ & $2(10)$ & $21(100)$ & \\
\hline Others & $19(10)(10.4)$ & $49(27)$ & $73(40)$ & $28(15)$ & $14(8)(7.6)$ & $183(100)$ & \\
\hline \multicolumn{8}{|l|}{ Activity during injury } \\
\hline Work & $2(1)$ & $45(30)$ & $63(42)$ & $30(20)$ & $10(7)(6.79)$ & $150(100)$ & \multirow[t]{4}{*}{$<0.001$} \\
\hline Travelling & $22(7)$ & $73(22)$ & $144(44)$ & $67(20)$ & $23(7)(7.0)$ & $329(100)$ & \\
\hline Sports & $10(56)(55.6)$ & 7 (39) & $01(5)$ & $0(0)$ & $0(0)$ & $18(100)$ & \\
\hline Others & $9(22)$ & $20(49)$ & $04(10)$ & $5(12)$ & $3(7)$ & $41(100)$ & \\
\hline \multicolumn{8}{|l|}{ Mechanism of injury } \\
\hline Road Traffic Crash & $22(7)$ & $75(22)$ & $143(43)$ & $68(20)$ & $28(8)$ & $336(100)$ & \multirow[t]{4}{*}{$<0.001$} \\
\hline Fall & $21(26)(25.9)$ & $22(27)$ & $24(30)$ & $14(17)$ & $0(0)$ & $80(100)$ & \\
\hline Quarrel & $0(0)$ & $33(30)$ & $48(44)$ & $21(19)$ & $8(7)$ & $110(100)$ & \\
\hline Others & $10(8)$ & $46(39)$ & $40(34)$ & $16(13)$ & $7(6)$ & $119(100)$ & \\
\hline
\end{tabular}

proforma which could be administered easily without hampering the routine schedule of the emergency department medical staff. A total of 4 medical officers were trained on the data collection proforma. They themselves trained other medical officers who were posted in rotation at the emergency department. In this pilot study at a district level hospital, around 14 injury cases reported to the emergency department in 1 week i.e. 2 cases per day. The nursing staff in the emergency department could be trained to fill the proforma which might hardly take $10 \mathrm{~min}$ for each. The data entry operator under IDSP at the district level could be used to enter the data which will hardly consume less than $30 \mathrm{~min}$ in a week. The district epidemiologist at the district level could be the nodal person overseeing the surveillance system. Thus, with the existing resources, we can establish a sustainable injury surveillance system at the district hospital level which will provide us with a large database on injury burden and characteristics in the country for effective decision making.

The missing values in various key variables suggest the need for better training and a comprehensive manual for those collecting data. The training and the manual should in detail highlight the significance of each variable collected. Variables such as time of injury, mode of transportation to the hospital, outcome of injury, alcohol use and substance use which had higher proportion of missing values need particular attention during training.

A major limitation of a hospital based surveillance is that the patients who reported an injury at the hospital are just a tip of the iceberg with fatal (on site of injury) cases missed and also substantial number of injury cases who do not avail health care services. Collecting injury related information from patients with severe injuries requiring immediate referral was a challenge because of time limitations as these were time critical. In such cases, important injury related information can be built in

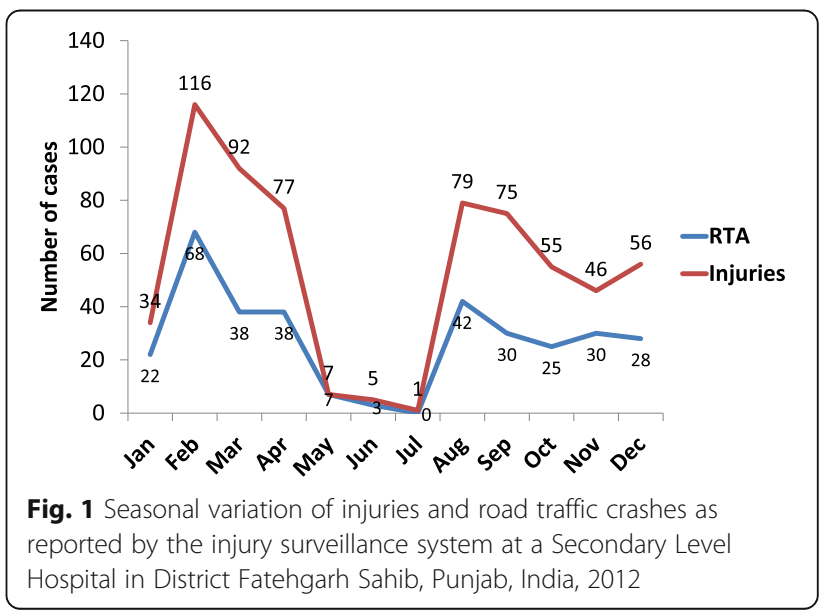


the referral form for quick capture. The injuries resulting in immediate death also might not have been reported to the hospital such as suicides due to hanging, drowning or road traffic crashes resulting in death at the place of the event itself. This will result in underestimation of injury burden. The research revealed limitations in record keeping of injury patients in the emergency department of a hospital. Although the EMOs were trained to fill the injury proforma but frequent change of emergency department staff and lack of motivation on the part of the EMOs were some of the problems encountered that suggests implications for the nurses working in the emergency department. There is high turnover of health personnel particularly doctors in the emergency department which hampers ongoing data collection. This issue was addressed through regular monitoring and periodic visits by the investigators wherein new medical officers were sensitized and trained about the surveillance system. However there is a need to incorporate injury surveillance as a routine feature in the emergency department.

\section{Conclusion}

Addressing the rising burden of injuries with competing healthy priorities and without robust data on injury burden and risk factors, is a major challenge for developing countries. There is need for various sectors like health, police, transport to come together and develop multifactorial intervention for injury prevention. Developing better and sustainable systems of routine injury surveillance or trauma registries is essential to generate reliable information for formulating effective intervention policies.

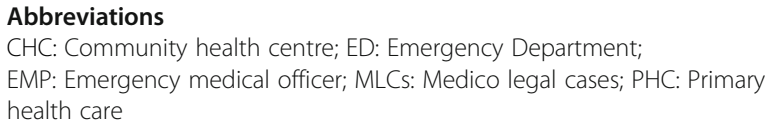

\section{Acknowledgement}

We greatly acknowledge the support from the Fatehgarh Sahib District Health Administration for providing the necessary manpower and logistic support to carry out this study.

\section{Funding}

Nil.

\section{Availability of data and materials}

Data is available with the corresponding author (PVML) and will be available on request at the following e-mail: pvm_lakshmi@yahoo.com.

\section{Authors' contribution}

PVML was responsible for conceptualization of idea, preparation of study proposal, study tool, interpretation of data and critical review of the manuscript. JPT was responsible for data collection, data analysis, interpretation of data and preparation of the manuscript. NKT was responsible for preparation of study tool, data collection, interpretation of data and critical review of the manuscript. SS and DB were responsible for collection and interpretation of data. RK was responsible for conceptualization of idea, preparation of study tool, interpretation of data and critical review of the manuscript. JJ was involved in preparation of study tool, interpretation of data and critical review of the manuscript. All authors read and approved the final manuscript.

\section{Competing interests}

The authors declare that they have no competing interests.

\section{Consent for publication}

All authors have consented for Publication.

\section{Ethics approval and consent to participate}

Appropriate approvals were obtained to conduct the study. Local administrative approval from the district and state health services of Punjab was obtained to conduct the study as the feasibility of injury surveillance was done as a pilot under Integrated Disease Surveillance Programme of Punjab.

\section{Author details}

${ }^{1}$ Department of Community Medicine \& School of Public Health, Post Graduate Institute of Medical Education \& Research, Chandigarh, India. ${ }^{2}$ International Union Against Tuberculosis and Lung Disease, The Union South East Asia Office, New Delhi, India. ${ }^{3}$ Kalinga Institute of Medical Sciences, Bhubaneswar, Odisha, India. ${ }^{4}$ Integrated Disease Surveillance Project, Punjab, India. ${ }^{5}$ Injury Division, The George Institute for Global Health, University of Sydney, Sydney, Australia.

Received: 14 May 2016 Accepted: 7 September 2016

Published online: 03 November 2016

\section{References}

Arscott-Mills S, Gordon G, McDonald A, Holder Y, Ward E. A profile of injuries in Jamaica. Inj Control Saf Promot. 2002;9(4):227-34.

Australian National Injury Surveillance Unit (NISU). Information needed for Injury prevention and control. Research Center for Injury Studies, Flinders University of South Australia collaborating Unit of Australia Institute of Health and Welfare. Available from: URL: http://www.flinders.edu.au/medicine/research/ centres/injury-studies/ (Last accessed on 20 May 2014).

Barber W, et al. Massachusetts Weapon-related Injury Surveillance System. Am J Prev Medicine. 1998;15(35):57-65.

Cardona M, Joshi R, Ivers RQ, lyengar S, Chow CK, Colman S, et al. The burden of fatal and non-fatal injury in rural. Inj Prev. 2008;14:232-7.

Chinh ND, Lap CD, Hiep ND, Son TH, Quyet NT, Quang N, et al. Preliminary results of injury surveillance at Viet Duc hospital. Thai J Surg. 2007;28:83-9.

Dandona R, Kumar GA, Raj TS, et al. Patterns of road traffic injuries in the vulnerable population in Hyderabad, India. InjPrev. 2006;12:183-8.

Deng X, Duan L, Wu C. Study on product-related injury surveillance in six hospitals in China. InjPrev. 2010;16(1):A39.

Fitzharris M, Yu J, Hammond N, Taylor C, Wu Y, Finfer S, Mybur J. Injury in China: a systematic review of injury surveillance studies conducted in Chinese hospital emergency departments. BMC Emergency Medicine. 2011;11:18.

Foltran F, Avossa F, Fedeli U, Baldi I, Spolaore P, Gregori D. Seasonal variations in injury rates in children: evidence from a 10-year study in the Veneto Region, Italy. Int J Inj Contr Saf Promot. 2013;20(3):254-8.

Forjuoh SN, Gyebi-Ofosu E. Injury surveillance: should it be a concern to developing countries? J Public Health Policy. 1993;14:355-9.

Ganveer GB, Tiwari RR. Injury pattern among non-fatal road traffic accident cases: a cross-sectional study in Central India. Indian J Med Sci. 2005;59:9-12.

Garg N, Hyder AA. Exploring the relationship between development and road traffic injuries: a case study from India. Eur J Pub Health. 2006;16:487-91.

Grivna M, Eid HO, Abu-Zidan FM. Epidemiology, morbidity and mortality from fall-related injuries in the United Arab Emirates. Scand J Trauma ResuscEmerg Med. 2014;22:51.

Halperin WE. The role of surveillance in the hierarchy of prevention. Am J Ind Med. 1996;29:321-3.

Hijar M, Carrillo C, Flores M, Anaya R, Lopez V. Risk factors in highway traffic accidents: a case control study. Accid Anal Prev. 2000;32(5):703-9. weekdays.

Holder Y, Peden M, Krug E, Lund J, Gururaj G, Kobusingye O. Injury surveillance guidelines. Centers for Disease Control and Prevention and World Health Organization. 2001. Available at: http://whqlibdoc.who.int/publications/2001/ 9241591331.pdf?ua=1.

Injuries and violence. The facts. Department of Violence and Injury Prevention and Disability, World Health Organization. 2010. [cited 2016 Aug 15]. Available from: http://apps.who.int/iris/bitstream/10665/44288/1/ 9789241599375_eng.pdf. 
Jirojwong S, Rudtanasudjatum K, Watcharavitoon P, Sathitsathien W, Sangjun S. Non-fatal injuries sustained in road traffic accidents: a pilot study in provincial hospitals in Chon Buri, Thailand. Southeast Asian J Trop Med Public Health. 2002;33(1):193-200.

John IA, Mohammed AZ, Lawoko S, Nkanta CA, Frank-Briggs A, Nwadiaro HC, et al. Implementing a hospital based injury surveillance system: a case study in Nigeria. Medicine, Conflict and Survival. 2008;24(4):273-9.

Kobusingye OC, Lett RR. Hospital-based trauma registries in Uganda. J Trauma. 2000;48(3):498-502.

Li GH, Baker SP. A comparison of injury death rates in China and the United States, 1986. Am J Public Health. 1991;81:605-9.

Mackenzie SG, Pless IB. CHIRPP: Canada's principal injury surveillance program. InjPrev. 1999;5:208-13.

Mohan D, Tsimhoni O, Sivak M, Flannagan MJ. Road safety in India: challenges and opportunities. Michigan: Transportation Research Institute, The University of Michigan; 2009. [cited 2016 Aug 15] Available from: http://environmentportal.in/ files/UMTRI-2009-1.pdf.

Morrison A, Stone DH, Doraiswamy N, Ramsay L. Injury surveillance in an accident and emergency department: a year in the life of CHIRPP. Arch Dis Child. 1999;80:533-6.

Mtonga RE, Zavala DE. Implementing a hospital based injury surveillance system in Zambia: a preliminary report. Medicine, Conflict and Survival. 2008:24(4):280-4.

Mulder S. Recording of home and leisure accidents: differences between population surveys and A\&E department surveillance systems. International Journal for Consumer Safety. 1997:4:165-78.

Musharrafieh U, Rahi AC, Taha A, Shamseddine W, Steitieh S, Jamali F, Tamim H. Profile of injured patients presenting to a tertiary hospital in a developing country. J Med Liban. 2011;59(4):191-6.

Ng ZX, Teo LT, Go KT, Yeo YT, Chiu MT. Major workplace related accidents in Singapore: a major trauma centre ¿s experience. Ann Acad Med Singapore. 2010;39:920-7.

Ricci G, Majori S, Mantovani W, Zappaterra A, Rocca G, Buonocore F. Prevalence of alcohol and drugs in urine of patients involved in road accidents. Journa of Preventive Medicine and Hygiene. 2008;49(2):89-95.

Santikarn C, Punyaratabandhu P, Podhipak A, et al. The establishment of injury surveillance in Thailand. Inj Control SafPromot. 1999;6:133-43.

Singh A, Goel A. Sekhar. Epidemiological Study of non-fatal road traffic accidents in Rohilkhand Region. Medico-Legal Update. 2011;11(1):5-9.

SPSS Inc. SPSS for Windows. Version 16.0. Chicago: SPSS Inc; 2007.

Tripathy NK, Jagnoor J, Patro BK, Dhillon MS, Kumar R. Epidemiology of falls among older adults: A cross sectional study from Chandigarh, India. Injury. 2015;46(9):1801-5.

Tuma MA, Acerra JR, El-Menyar A, Al-Thani H, Al-Hassani A, Recicar JF, Al Yazeedi W, Maull Kl. Epidemiology of workplace-related fall from height and cost of trauma care in Qatar. Int J CritlllnInjSci. 2013;3:3-7.

Uthkarsh PS, Suryanarayana SP, Gautham MS, Shivraj NS, Murthy NS, Pruthvish S. Profile of injury cases admitted to a tertiary level hospital in South India. Int J Inj Contr Saf Promot. 2012;19(1):47-51.

Ward E, Durant T, Thompson M, Gordon G, Mitchell W, Ashley D, the VRISS. Implementing a hospital-based Violence-Related Injury Surveillance System a background to the Jamaican experience. Inj Control and Safety Promot. 2002;9(4):241-47.

WHO Global Report on Falls Prevention in Older Age. Geneva: World Health Organization; 2007. Available at http://www.who.int/ageing/publications/ Falls_prevention7March.pdf.

Wikipedia contributors. Medicolegal. Wikipedia, The Free Encyclopedia. March 28, 2013, 06:30 UTC. Available at: https://en.wikipedia.org/wiki/Medicolegal. [Last accessed on 6 Nov 2015]

Yamuragiye A, Ibambasi A, Mutuyimana A, Mutuyemariya O, Nsereko E. Injury profile in an emergency department at a referral hospital in Kigali, Rwanda. Rwanda j health sci. 2013;2(1):61-2.

Zavala DE, BokongoS JIA, MpangSenoga I, Mtonga RE, Mohammed AZ, et al. Implementing a hospital based injury surveillance system in Africa: lessons learned, Medicine. Conflict and Survival. 2008:4(4):260-72.

\section{Submit your manuscript to a SpringerOpen ${ }^{\circ}$ journal and benefit from:}

- Convenient online submission

- Rigorous peer review

- Immediate publication on acceptance

- Open access: articles freely available online

- High visibility within the field

- Retaining the copyright to your article

Submit your next manuscript at $>$ springeropen.com 